\title{
Important Prospect: The World Climate Conference *
}

A World Climate Conference (WCC)-'A Conference of Experts on Climate and Mankind'-will be convened by the World Meteorological Organization (WMO) during the period 12-23 February 1979 in Geneva, Switzerland. There have been many scientific and technical conferences on the physical and geophysical aspects of climate. In contrast, the World Climate Conference will attempt to provide a definitive assessment of our current knowledge of climate, and integrate this knowledge with knowledge from other disciplines in order to extend our understanding of the impacts of climatic change and variability on human activities and on our environment.

This Conference is a response by WMO and other U.N. agencies to the growing world-wide concern about the impacts of natural variations in climate upon world food production, energy supply and demand, water resources, land-use, and other aspects of socicty. It is also a response to the ominous indications that Man, through his own activities, may cause significant changes in climate. There are now sufficient indications that some of these potential changes, such as those that might result from increased amounts of atmospheric carbon dioxide $\dagger$, could have a pervasive impact upon the nations of the world and may require unprecedented forms of international action to deal with effectively.

The topics which will be examined fall naturally within the interests and expertise of many different international organizations. The Conference, therefore, is a collaborative effort of the World Meteorological Organization and other international bodies. Sessions dealing with agriculture, forestry, and fisheries, have been organized in conjunction with the Food and Agriculture Organization (FAO). The United Nations Education, Scientific, and Cultural Organization (UNESCO) has assisted in the organization of the sessions dealing with global ecology and marine resources. The World Health Organization (WHO) has participated in the organization of sessions dealing with climate and health. The United Nations Environment Programme (UNEP), having a broad interest in all these and some other topics, has provided support for many sessions and activities of the World Climate Conference.

The WCC is the first stage in an international effort to address a wide range of growing concerns related to climatic change and variability. The greatest part of this effort will revolve around the World Climate Programme** which WMO is also planning in collaboration with other international, intergovernmental, and nongovernmental, organizations. This programme will be the vehicle for implementing international plans of action in climate science, climate data and applications, and research on the impacts of climate on society and the environment. Through the World Climate Programme, individual nations will set in motion programmes to take greater advantage of favourable aspects of climate and to mitigate adverse impacts. The conclusions, recommendations, and plans of action, adopted by the Conference, will be of

\footnotetext{
* Following principally the WMO Bulletin on the World Climate Conference.

† See the paper on 'Energy and Climate', by Professor Roger R. Revelle \& Dr Donald C. Shapero, published in our Summer issue this year (Environmental Conservation, Vol. 5, No. 2, pp. 81-91, 1978.-Ed.).

** See Dr William W. Kellogg's 'Introduction to the World Climate Programme', published on pages 293-4 of this issue.-Ed.
}

particular value because these will influence the shape and character of the World Climate Programme in substantial ways.

An International Organizing Committee has developed a provisional programme for the World Climate Conference. During the first week of the Conference, twenty-four overview papers on the various scientific aspects of climate and the impacts of climate on mankind will be presented in plenary sessions by leading authorities. These reports will review the state of knowledge in each topic and define specific issues for discussion by the participants in the Conference. Discussion of the papers by the plenary sessions will serve as the basis for the findings, recommendations, and plans of action, of the Conference.

During the second week of the WCC, invited experts (approximately 100 in number) will, together with the overview speakers, participate in a series of working groups which will formulate in detail the Conference findings and recommendations. These will be brought to the attention of the eighth session of the WMO Congress, which will be held in Geneva in April and May of 1979.

The Executive Committee of WMO has also requested the Conference to consider the desirability of convening a United Nations Conference on Climate at the Ministerial Level. The WCC will, therefore, formulate a recommendation on the need for such a conference on the basis of its assessment of climatic impacts and the outlook for the future.

As the Conference title suggests, this will be a meeting of experts, all attending in a personal capacity and not as representatives of their governments. All invited speakers and participants will be chosen on the basis of the expertise that they can bring to these important deliberations. Invited participants are selected with a view to providing widespread geographical representation and knowledge in a wide spectrum of physical and social sciences. It must be emphasized that the World Climate Conference is not a specialized meteorological conference: it is being convened to examine the relationship of climate to human activity and the human environment.

The first week of the Conference will be open, to the extent possible, to participation by all interested and qualified individuals. Individuals can request permission to attend by writing to the Secretary-General of WMO, Case Postale No. 5, 1211 Geneva 20, Switzerland, outlining their organizational affiliation and the nature of their interest in climate. During the plenary discussions-at the discretion of the chairmen of the individual sessions-discussion, comments, and questions, from both the invited experts and the other participants, will be entertained. The findings and recommendations of the Conference will therefore reflect a broad spectrum of views.
ROBERT M. WhITE, Chairman
Organizing Committee for the World Climate Conference
World Meteorological Organization
Case Postale No. 5
1211 Geneva 20
Switzerland,
\&
Climate Research Board
National Academy of Sciences
2101 Constitution Avenue
Washington
D.C. 20418, U.S.A. 